\title{
Correction to: The effect of financial scarcity on discretionary spending, borrowing, and investing
}

\author{
Gülen Sarial-Abi ${ }^{1} \oplus$. Aulona Ulqinaku² $\cdot$ Giampaolo Viglia ${ }^{3,4} \cdot$ Gopal Das $^{5}$
}

C Academy of Marketing Science 2021

\section{Correction to: Journal of the Academy of Marketing Science https://doi.org/10.1007/s11747-021-00811-0}

In the original version of this article, the given and family names of Gülen Sarial-Abi were incorrectly structured. The name was displayed correctly in all versions at the time of publication.

The original article has been corrected.

Publisher's Note Springer Nature remains neutral with regard to jurisdictional claims in published maps and institutional affiliations.

The original article can be found online at https://doi.org/10.1007/ s11747-021-00811-0.

Gülen Sarial-Abi

gsa.marktg@cbs.dk

Aulona Ulqinaku

A.Ulqinaku@leeds.ac.uk

Giampaolo Viglia

giampaolo.viglia@port.ac.uk

Gopal Das

gopal.das@iimb.ac.in

1 Marketing Department, Copenhagen Business School, Solbjerg Plads 3, 2000 Frederiksberg, Denmark

2 Leeds University Business School, University of Leeds, Maurice Keyworth Building, (LUBS G07), Leeds, UK

3 Marketing Department, University of Portsmouth, Richmond Building, Portmouth PO13DE, UK

4 Department of Economics and Political Science, University of Aosta Valley, Street Cappuccini 2, 11100 Aosta, Italy

5 Department of Marketing, Indian Institute of Management Bangalore, Bannerghatta Road, Bangalore 560075, India 